\title{
Tid för förändring av arbetsvillkor inom vård och omsorg
}

\author{
Tid och temporalitet $i$ narrativt meningsskapande under den \\ forsta tiden av coronapandemin
}

\begin{abstract}
Time for changed working conditions within the health care sector. Time and temporality in narrative sensemaking during the first phase of the corona pandemic in Sweden.

In the present study, we focus on stories about working conditions in the Swedish health care sector during the initial phase of the corona pandemic in the spring of 2020. The study is based on 33 interviews with health care professionals conducted during the first weeks of the corona pandemic. By linking interpretations of narratives to time and temporality in the analysis, we analyze how stories about working conditions relate to managing the effects of the pandemic as well as to working conditions before and after the pandemic. Narrative analysis shows that different perspectives on time are used to support the argumentation in the participants' stories. One perspective is linked to the specific situation of the first phase of the corona pandemic and the other relates to the work situation during the corona pandemic as part of an, in time, extended context. The analysis with a focus on time and temporality in the stories creates an opening to understand the corona pandemic as an event that draws attention to something more than the work situation right now, namely a critique of working conditions on a general level.
\end{abstract}

Keywords: narrative analysis, sensemaking, temporality, time, working conditions

I FÖRELIGGANDE STUDIE undersöker vi berättelser om arbetsvillkor inom svensk vård och omsorg under den inledande fasen av coronapandemin under våren 2020. Vi gör detta med utgångspunkt i en intervjustudie som genomfördes under de allra första veckorna efter det att världshälsoorganisationen (WHO) den 11 mars 2020 definierat den pågående och världsomfattande smittspridningen av coronaviruset (SARS-CoV-2) som en pandemi. Studien bygger vidare på en deskriptiv innehållsanalys av arbetssituationen för personal inom vård och omsorg (Wall 2020a). Resultatet från den deskriptiva analysen visar på behov av förbättrade arbetsvillkor för personal inom vård och omsorg, för att möta de förändringar som den akuta situationen kring hanteringen av pandemin skapade (Wall 2020a). Utgångspunkten för analysen i denna artikel är ett intresse för hur deltagarna i sina berättelser om förbättrade arbetsvillkor inte 
enbart relaterade till situationen just nu utan också till arbetsvillkor före och efter coronapandemin. Detta väckte teoretiska frågor kring betydelsen av hur tid används och ordnas i individers meningsskapande under akut uppkomna situationer.

Vi utgår här från sociologisk teori om meningsskapande i organisationer (Weick 1995) och undersöker hur meningsskapande uttrycks genom narrativ i berättelser (Czarniawska 1997) med särskilt avseende på hur den meningsskapande processen knyts till och ordnas i relation till tid (Cunliffe, Luhmann \& Boje 2004; Pedersen 2009). Mot denna bakgrund undersöker vi betydelsen av tid och temporalitet - det vill säga hur tid förstås, används och ordnas - i det narrativa meningsskapande som den plötsliga pandemin gav upphov till och hur denna situation relaterar till arbetsvillkor före, under och efter pandemin. Att vård och omsorg utmanas särskilt vid global smittspridning har visats i tidigare forskning om utbrotten av SARS, MERS och ebola. Denna forskning har uppmärksammat hög arbetsbelastning, förändrade arbetsuppgifter och nya förutsättningar för arbetet (Maunder, Leszcz, Savage m.fl. 2008) men också utmaningar relaterade till personlig utsatthet för smitta och ohälsa till följd av emotionellt utmanande arbete (Maunder, Hunter, Vincent m.fl. 2003; Koh, Lim, Chia m.fl. 2005; McAlonan, Lee, Cheung m.fl. 2007; Son, Erno, Shea m.fl. 2007; Wu, Fang, Guan m.fl. 2009). Tidigare studier som belyst hanteringen av plötsligt förändrade villkor har lyft fram betydelsen av tillgång till utrustning (till exempel skyddsutrustning) (Maunder, Hunter, Vincent m.fl. 2003; Maunder 2004; Lee, Juang, Su m.fl. 2005; O’Boyle, Roberston \& Secor-Turner 2006; Speroni, Seibert \& Mallinson 2015a, 2015b; Son m.fl. 2019), adekvat och tillräcklig information (Speroni, Seibert \& Mallinson 2015a, 2015b), att vårdpersonal bör delta i beslutsprocesser på övergripande nivå (Tolomiczenko, Kahan, Ricci m.fl. 2005; Son, Lee, Kim m.fl., 2019) samt att kommunikation på arbetsplatsen tillmäts en viktig roll (Chan \& Huak 2004; Tam, Pang, Lam m.fl. 2004; Wong, Yau, Chan m.fl. 2005; Khalid, Khalid, Qabajah m.fl. 2016). Under tider av hög belastning är det också betydelsefullt hur arbetstiden förläggs och att utrymme för återhämtning möjliggörs (Chan, Leung, Tiwari m.fl. 2005). För att möta oväntade händelser krävs att personalen ges förutsättningar genom bland annat utbildning och träning (Rieckert, Schuit, Bleijenberg m.fl. 2021). Utifrån en översikt av forskning om vårdens arbetsvillkor under pågående utbrott av smittsamma sjukdomar (covid-19, SARS, MERS och ebola) framhåller Rieckert med kollegor (2021) att frågan om arbetsvillkor inom vård och omsorg inte kan begränsas till hantering av specifika utmaningar kopplade till coronapandemin. De betonar att generella arbetsvillkor (arbetsuppgifter, ansvar, intensitet i arbetet, arbetsförhållanden) är avgörande för hur vård och omsorg kan hantera akut uppkomna situationer vid global smittspridning (Rieckert, Schuit, Bleijenberg m.fl. 2021).

De berättelser om arbetssituationen inom svensk vård- och omsorgssektor under coronapandemin som här analyseras handlar om den organisatoriska kontext inom vilken personalen arbetar och den utveckling som präglat denna sektor under en lång tid. Under 1980- och 1990-talen påbörjades en övergripande förändringsprocess av den svenska vårdapparatens organisering som ledde till nedskärningar och privatiseringar (Hansen 2014), vilket följde på den privatiseringsvåg som präglat hela västvärlden 
under de senaste decennierna (Hall 2012). Samtidigt med den ökade marknadiseringen av vård- och omsorgssektorn under tidigt 1990-tal (Bäck \& Gröjer 1994; Öhrming \& Sverke 2001) förändrades arbetsvillkoren för personalen inom denna sektor. Personalen rapporterade ökade krav i arbetet (Målqvist, Åborg \& Forsman 2011), försämrad autonomi (Bejerot \& Hasselbladh 2013) och en ökad upplevelse av otillräcklighet (Arbetarskyddsstyrelsen 2000). Personalens egen hälsa påverkades också negativt under denna förändringsprocess vilket yttrade sig i högre sjuktal och mer frekvent rapporterad ohälsa (Grassi \& Magnani 2000; Fridner, Belkic, Minucci m.fl. 2009, 2011). Tidigare analyser av arbetsvillkoren inom vården har konstaterat att de anställdas hälsa och välbefinnande bör ges större vikt (Hansen 2014), inte minst för att säkerställda en god vårdkvalitet (Williamsson 2007; Hansen 2014). När det gäller hanteringen av coronapandemin har WHO speciellt uppmärksammat personalen inom vård och omsorg som en särskilt central grupp att skydda (WHO 2020).

Syftet med föreliggande studie är att analysera tid och temporalitet i narrativt meningsskapande och hur detta kan hjälpa oss att förstå den akut uppkomna arbetssituationen inom vård och omsorg under coronapandemin.

\section{Teoretiska utgångspunkter}

För att analysera arbetsvillkoren under den första tiden av coronapandemin tar vi avstamp i teorier om meningsskapande i organisationer (Weick 1995) och den förståelse av berättelser som uttryck för meningsskapande som görs inom narrativ organisationsforskning (Czarniawska 1997). Meningsskapande definieras av Weick med kollegor som den tolkningsprocess som uppstår i mötet med en situation som inte kan förstås och förklaras direkt (Weick 1995; Weick, Sutcliffe \& Obstfeld 2005). Liksom för andra teoretiska begrepp som används inom ett flertal vetenskapliga discipliner skiljer sig också tolkningarna av detta begrepp. Det finns exempel där begreppets innebörd reduceras till den enskilde individens kognitiva förmåga (Starbuck \& Millikien 1988; Klein, Moon \& Hoffman 2006) medan man inom sociologin oftast framhåller de sociala aspekterna av begreppet och vanligen definierar meningsskapande som ett socialt konstruerat fenomen (Weick 1995; Maitlis 2005; Wall 2010). Här lyfts den ömsesidiga relationen fram mellan individen och organisationen och organisationens förmåga att hantera oväntade händelser förstås som ett uttryck för hur mening skapas hos de individer som bygger upp organisationen (Sandberg \& Tsoukas 2014). Vi ansluter till detta perspektiv, där relationen mellan individen och dess omgivning står i fokus. Utifrån detta perspektiv är det också möjligt att knyta meningsskapande till organisationsförändringar, då organisationen förstås som en serie händelser och där nästa steg i processen ständigt karaktäriseras av att innehålla element av osäkerhet (Weick, Sutcliffe \& Obstfeld 2005).

Weick menar att något som är nödvändigt för meningsskapande "is a good story" (Weick 1995:60-61 i Czarniawska 2005:272) vilket knyter detta perspektiv till narrativ teori. Narrativ kunskap utgår från att vi skapar mening av våra upplevelser och erfarenheter genom sammanvävda, och i en viss följd ordnade, beskrivningar eller 
berättelser (Polkinghorne 1988; Weick 1995 i Cunliffe, Luhmann \& Boje 2004:263). För att förmedla en förståelse av komplexa samhälleliga mönster av social interaktion använder sig människor av berättelser som samlar erfarenheter (Bruner 1991; Currie \& Brown 2003:564). Det är genom narrativ vi människor skapar mening och det är genom berättelser våra erfarenheter görs meningsfulla (Polkinghorne 1988:1; Brown, Stacey \& Nandhakumar 2008:1039). Narrativt meningsskapande kan då beskrivas som den tolkningsprocess och produktion av mening genom vilken människor reflekterar och tolkar olika fenomen genom berättelser (Leiter 1980; Currie \& Brown 2003:564). Människor använder sig av meningsskapande narrativ för att organisera sin förståelse av verkligheten (Wilkins \& Thompson 1991:20). En utgångspunkt när människors meningsskapande vid förändringar i organisationer analyseras är därför att man bör studera det som narrativ om och i förändring (Pedersen 2009:391). De upplevelser och erfarenheter av en situation som framkommer i sådana narrativ kan förstås både utifrån berättelsernas innehåll och hur de framställs. MacIntyre (1981 i Ewick \& Silbey 1995:198) visar hur den narrativa framställningen relaterar såväl till sensmoral som till hur berättelsen organiseras i relation till tid. Detta knyter det narrativa meningsskapandet till tid och temporalitet genom hur berättelser relateras till tidsförlopp och organiseras utifrån en viss tidsordning.

Hur vi konstruerar och skapar förståelse kring våra erfarenheter och oss själva, $\mathrm{i}$ relation till andra och i och genom tid kan beskrivas som narrativ temporalitet (Cunliffe, Luhmann \& Boje 2004:281). Tid, som teoretiskt begrepp, öppnar också upp för andra förståelser av tid i meningsskapande narrativ än de rent kronologiska (Pedersen 2009:390). Cunliffe, Luhmann och Boje (2004:269) menar att vi skapar mening kring det som händer nu genom att knyta an till erfarenheter såväl som till vad vi tror om framtiden. När vi reflekterar över tidigare händelser påverkas våra tolkningar både av det som sker i nuet och vad vi tror om framtiden (Cunliffe, Luhmann \& Boje 2004:274). Utifrån Ricoeur (1984) menar Cunliffe, Luhmann och Boje (2004:269) att dåtiden inte längre existerar i sig självt, eftersom vi tolkar den genom våra upplevelser av det som händer nu. På motsvarande sätt existerar framtiden bara som förväntan och tillfället "nu" ska ses som en övergång från dåtid till nutid. Med andra ord använder vi både erfarenheter och upplevelser i nutid och dåtid för att förstå det som händer nu och vad som hände då, och för att förutse vad som kan ske i framtiden (Cunliffe, Luhmann \& Boje 2004:269). Dessa teoretiska perspektiv på tid gör det möjligt att analysera hur narrativ om förändringar kan förstås utifrån olika sätt att relatera till tid och till hur berättelser ordnas tidsmässigt kring ett specifikt händelseförlopp (Pedersen 2009:390).

Tid har också en central plats i teorier om meningsskapande. Weicks perspektiv (Weick 1995; Weick, Sutcliffe \& Obstfeld 2005) bygger på att människors förutsättningar att skapa mening ramas in av tidigare erfarenheter (Starbuck \& Milliken 1988). För att skapa förutsättningar att analysera betydelsen av en mer utsträckt tid för narrativt meningsskapande väljer vi här att utgå från Petranker (2005) som menar att tidigare narrativ organisationsteori (Czarniawska 1997) och teori om meningsskapande i organisationer (Weick 1995) i alltför hög grad låst sig fast vid betydelsen av tidigare erfarenheter vid tolkningar av de situationer som uppstår. Petranker (2005:242) pekar 
på betydelsen av att föreställningar om framtiden måste inkluderas vid tolkningen av det som händer nu. Specifikt i relation till meningsskapande har det betonats att det är viktigt att inkludera såväl tidigare erfarenheter som tolkningar av nuet och de idéer man har om framtiden när skapandet av mening studeras (Gioia 2006; Ybema 2010; Corley \& Gioia 2011; Brown, Colville \& Pye 2015).

Utifrån vår förståelse av narrativt meningsskapande lyfter vi i artikelns analys särskilt fram betydelsen av hur tid används och ordnas, samtidigt som vi betonar att narrativ kunskap skapas i specifika situationer, sammanhang och omständigheter (Cunliffe, Luhmann \& Boje 2004:273). Konkret innebär det att vår analys av narrativt meningsskapande i berättelser om vårdens och omsorgens arbetsvillkor under den första tiden av coronapandemin fokuserar på betydelsen av hur tid används som ett stöd för att skapa mening i den akut uppkomna situationen. Detta görs med utgångspunkt i teorier om hur meningsskapande sker under större organisationsförändringar (Weick 1995) och hur det detta meningsskapande kan analyseras med hjälp av narrativ (Czarniawska 1997). Genom att i analysen knyta tolkningar av narrativ till teorier om tid (Cunliffe, Luhmann \& Boje 2004; Pedersen 2009) analyseras hur berättelser om arbetsvillkor relaterar till tiden före, under och efter coronapandemin.

\section{Metod}

\section{Datainsamling}

Studien baseras på intervjuer med vårdpersonal som genomfördes under de första veckorna av coronapandemin. Intervjuerna gjordes i ett specifikt och akut sammanhang, nämligen den allra första tiden av coronapandemin. Datainsamlingen genomfördes av Erika Wall inom hennes ordinarie tjänst och artikeln har skrivits inom ramen för ett forskningsprojekt finansierat av AFA Försäkring med titeln "Vårdpersonalens coronavardag" (Wall 2020b).

Under perioden 16 mars till 5 maj 2020 genomfördes intervjuer med 33 personer yrkesverksamma inom vård- och omsorgssektorn i Sverige: 12 undersköterskor, 13 sjuksköterskor, 7 läkare samt 1 person med annat yrke inom vården. Materialet inkluderar personer från hela vård- och omsorgssektorn och innehåller därmed erfarenheter från arbete inom verksamheter som regleras av hälso- och sjukvårdslagen såväl som socialtjänstlagen. Berättelserna handlar om arbete inom akutsjukvård (8 personer), sjukhusvård (8 personer), olika slags boenden inom vård- och omsorgssektorn (äldreboenden, demensboenden, LSS-boenden etc.) (10 personer) och annan verksamhet inom vård och omsorg (7 personer). Materialet inkluderar erfarenheter från akut- och intensivvård med covid-19-infekterade patienter och intervjuer med personer som arbetat $\mathrm{i}$ miljöer med och utan misstänkt smitta. Ingen intervjuperson framstod som opåverkad av hanteringen för minskad smittspridning av coronaviruset. Majoriteten av intervjuerna genomfördes med vårdpersonal från Stockholmsområdet, där man vid denna tid hade flest personer med bekräftad covid-19-infektion i Sverige. Då rekryteringen av deltagare inte avgränsades till någon specifik region innehåller dock materialet berät- 
telser från alla delar av landet samt från verksamheter inom storstadsområden, städer, större och mindre samhällen samt i något fall mindre samhällen. Av etiska skäl ställdes inga personliga frågor vid intervjuerna men majoriteten av deltagarna uppfattades vara kvinnor och de flesta föreföll vara i medelåldern.

Rekryteringen av intervjupersoner skedde genom annonsering i sociala medier och genom information i tidskrifter som vänder sig till vårdpersonal (Vårdfokus, Äldre $i$ centrum etc.). Via en rekryteringssida på Mittuniversitetets hemsida gavs information om datainsamlingen (utformad i enlighet med Vetenskapsrådets riktlinjer för forskningspersonsinformation, Vetenskapsrådet 2017) och intresserade kunde anmäla samtycke till deltagande och hantering av data i enlighet med GDPR. Intervjupersonerna deltog i studien inom ramen för sin profession och tillfrågades enbart om arbetet under de första veckorna av coronapandemin. Inga frågor ställdes som kan användas för att spåra vilken specifik arbetsplats som avses, om patienter/boenden eller av privat karaktär. Utifrån detta har bedömningen gjorts att studien inte lyder under lagen för etikprövning.

Intervjuerna genomfördes alla av en och samma forskare (Wall). I enlighet med de riktlinjer om att hålla avstånd från varandra som var gällande vid denna tid genomfördes samtliga intervjuerna via telefon. Till stöd för datainsamlingen användes en intervjuguide utifrån vilken intervjupersonerna ombads att återberätta sin senaste arbetsdag i detalj. Dessutom ställdes ett antal frågor med syfte att ge material om på vilka sätt smittspridningen av coronaviruset hade påverkat arbetet samt frågor om vad man ansåg att arbetsgivare respektive myndigheter och beslutsfattare behövde veta om arbetsvillkoren för vårdpersonal under den första tiden av coronapandemin. Alla intervjuer utom en spelades in, efter att deltagarna muntligen gett sitt uttryckliga samtycke. Intervjuerna transkriberades ordagrant.

\section{Analysmetod}

Det material som ligger till grund för analysen i denna artikel är avgränsat till de transkriberade svaren på den sista frågan i intervjuerna, där deltagarna ombads ge uttryck för vad de menade att myndigheter och beslutsfattare behövde veta om arbetsvillkoren inom vården för att bättre kunna ge stöd under coronapandemin ("Vad behöver myndigheter och beslutsfattare veta om din arbetssituation för att bättre kunna ge stöd under denna situation?”). En deskriptiv innehållsanalys av denna del av materialet har tidigare publicerats (Wall 2020a). Genom att här fokusera på betydelsen av hur tid används och ordnas i individers narrativa meningsskapande bidrar föreliggande artikel med en fördjupad analys av materialet.

Utgångspunkten för föreliggande analys är att utsagorna kan förstås som enskilda narrativ som speglar vårdpersonalens upplevelsevärld (Johansson 2005; Holley \& Colyar 2009; McAlpine 2016). Dessa enskilda berättelser känns igen av att de har en början, en mitt och ett slut och ofta sammanfattar ett huvudbudskap. Denna avslutning, eller "poängen med berättelsen" (Czarniawska 1997), kan förstås som ett uttryck för vad berättaren gör med berättelsen (Labov \& Franshel 1977). I det material som analyseras här skapar själva intervjufrågan en förväntan om ett budskap som 
riktas till en tänkt motpart, eftersom intervjupersonerna uppmuntras att delge sin syn på vad myndigheter och beslutsfattare behöver veta om arbetssituationen just nu. Svaret på en sådan fråga uppmuntrar till en kort berättelse med en avslutande poäng vilket bidrar till utsagornas narrativa karaktär. Genom att fokusera på berättelserna och berättandet är det möjligt att analysera hur uppfattningar konstrueras och kommuniceras (Johansson 2005). Den narrativa analysen med sitt fokus på berättelsens delar ger också möjlighet att nå kunskap om tid och hur tid används och ordnas i ett narrativ. Som Hydén (1997) uttrycker det:

tiden eller den temporala dimensionen är central för vår uppfattning om vad en berättelse är och vad som händer i en berättelse. Vi placerar händelser på en tidsaxel, och ordningen på denna tidsaxel är avgörande för tolkningen av händelsernas innebörd. (Hydén 1997:22, kursivering i original).

För att fånga narrativt meningsskapande i relation till tid vad gäller arbetsvillkor inom vården under den första tiden av coronapandemin görs här en narrativ analys utifrån vilken narrativa vinjetter skapas och presenteras. Skapandet av vinjetter innebär att forskaren intar den aktiva positionen som berättare (jämför med Smith 2016). Narrativa utsagor från olika personer med varierande erfarenheter knyts samman till gemensamma berättelser (Ekengren, Stambulova, Johnson m.fl. 2020:4), så kallade vinjetter (Hings, Wagstaff, Anderson m.fl. 2018) som ett sätt att undersöka människors uppfattningar och meningsskapande kring specifika situationer (Barter \& Renold 1999). Att som forskare skapa vinjetter, alltså kompakta berättelser som återger deltagarnas erfarenheter, utgör således en central del av analysprocessen (Spalding \& Phillips 2007; Schinke, Blodgett, McGannon m.fl. 2016; Hings, Wagstaff, Anderson m.fl. 2018).

Skapandet av vinjetter inleds här med att vi utformar ett empiriskt grundmaterial (jämför med Schinke, Blodgett, McGannon m.fl. 2016; Hings, Wagstaff, Anderson m.fl. 2018). Först markerar vi uttryck för tid i hela det empiriska materialet. Därefter undersöks hur poängen i berättelsen (jämför med Czarniawska 1997) i varje enskilt narrativ relateras till markerade utsagor om tid och hur tid används och ordnas, samt vilka mönster i materialet detta ger upphov till. En ytterligare fördjupning görs därefter genom att analysera vilka perspektiv på narrativt meningsskapande av arbetsvillkor som framträder när det tidssorterade materialet undersöks i fråga om gemensamma berättelser. I denna process ställer vi oss frågor vilka enligt Holley och Colyar (2009) är väsentliga när narrativ ska återges i reducerad form: Vilken är den huvudsakliga handlingen? Hur hänger berättelser om händelseförlopp och förståelse ihop? I denna analysprocess skapas de första utkasten till vinjetter baserat på allt det empiriska material som kodats utifrån poängen i berättelsen i relation till hur tid används och ordnas. Ingen del av materialet väljs bort. Citat från respektive intervju hålls samman och knyts till endast en specifik vinjett. Dessa utkast presenteras som fullständiga citat klippta ur intervjuerna (Ely, Vinz, Downing m.fl. 1997). Genom diskussioner om relevans och jämförelser mellan de vinjetter som skapats justeras och förfinas innehållet. När 
båda författare är överens om innehållet i respektive vinjett och vad detta säger om meningsskapande i den specifika situationen genomförs den sista bearbetningen, där innehållet i vinjetterna reduceras för att visualisera de gemensamma berättelserna. I detta sista steg justeras också språket i vinjetterna genom att citat kortas av och att småord mellan vissa satser läggs till för att få ett bättre flyt (jämför med Hings, Wagstaff, Anderson m.fl. 2018). Dessa slutliga vinjetter ger uttryck för gemensamma berättelser i förenklad form och består av avkortade citat hämtade från intervjuerna (jämför med Spalding \& Phillips 2007; Churchman \& King 2009; McAlpine 2016; Schinke, Blodgett, McGannon m.fl. 2016; Hings, Wagstaff, Anderson m.fl. 2018).

\section{Resultat och analys}

Olika perspektiv på användningen av tid i berättelser om arbetssituationen just nu I föreliggande analys fördjupas förståelsen av narrativt meningsskapande genom fokus på hur intervjupersoner inom vård och omsorg förmedlar berättelser om arbetssituationen under den första tiden av coronapandemin i relation till hur tid används och ordnas. Analysen visar att olika perspektiv på tid används som stöd för argumentationen i deltagarnas utsagor. Ett mönster framkom där Dåtid, Nutid och Framtid på olika sätt lade grund för poänger om Nutid respektive Framtid. Tillsammans synliggör dessa mönster narrativt meningsskapande i relation till tid. Det första perspektivet, som presenteras nedan, betonar det specifika i situationen medan det andra perspektivet relaterar till arbetssituationen under coronapandemin som en del av ett i tid utsträckt sammanhang. Dessa båda gemensamma berättelser baseras på de citat som ingått i analysen och presenteras som vinjetter nedan. Efter denna inledande visualisering av de centrala tidsperspektiv som framkommit, som grund för narrativt meningsskapande av arbetsvillkor inom vård och omsorg under den första tiden av coronapandemin, följer en fördjupad analys.

\section{Situationen just nu förstås som specifik}

\section{Vinjett I}

Det är på IVA det händer, det är häftig vård och där är man avancerad. Men då tänker jag på äldreboendena som har hamnat i skymundan. Det är där vi har våra allra sköraste. Alltså, att många säger så här att liksom sjukvården är fronten. Men på något sätt känner jag: Nej, det är sista försvaret. Det praktiska arbetet som händer inom vården - det skulle jag vilja att myndigheterna vet hur det ser ut. Att de har varit närvarande på golvet. Det här att faktiskt veta hur det ser ut, hur en arbetsdag ser ut. Ja, och att de får reda på att vi inte är testade och att vi inte har tillräckligt med skyddsutrustning. Nu testar man ingen sjukvårdspersonal, så man har ingen aning om hur många i sjukvården som faktiskt har blivit sjuka i corona. Jag tycker också att det måste bli hårdare restriktioner nu i dessa tider. Jag skulle vilja se mycket striktare åtgärder från myndigheternas sida, för att jag 
upplever det som att folk tror att det här är över. Problemet för oss blir längre fram. Okej, det här håller på april, maj ut. Och när tänker resten av sjukvården komma i gång med allt annat igen?

Denna första vinjett visar hur det narrativa meningsskapandet av arbetssituationen är knuten till den akuta fasen av coronapandemin, just $n u$. Vinjetten synliggör hur man ser på förutsättningarna framåt, både utifrån hur situationen upplevs just nu och vad man tänker om en framtid specifikt relaterad till den akuta situationen. I vinjetten framträder en bild av hur arbetsvillkoren under pågående pandemi förstås i termer av akut anpassning till den rådande situationen (Nutid), där budskapet handlar om att myndigheter, beslutsfattare och samhället behöver sätta sig in i hur situationen ser ut i praktiken och ge stöd genom att bidra till att spridningen av viruset begränsas. Det narrativa meningsskapandet av den akuta situationen relateras till en tänkt framtid. En oro över förutsättningarna att hantera situationen över tid framträder, liksom idéer om hur en bättre beredskap för liknande akuta situationer kan skapas. Detta görs genom att påpeka att problemen kommer längre fram och att den akuta situationen med coronapandemin kommer att få efterverkningar för vården senare (Framtid). Dessa mönster, vad gäller tid som grund för poängen i berättelsen, kan beskrivas enligt följande:

Nutid som grund för poäng om Nutid

Nutid som grund för poäng om Framtid

Framtid som grund för poäng om Framtid

\section{Situationen just nu förstås som del av en långvarig process}

\section{Vinjett II}

Problemet i dag är ju att vi har en hälso- och sjukvård som har monterats ner under lång tid. Vi har under många år jobbat med en kapacitet som inte motsvarar det behov som finns. Man har ju nedmonterat beredskapen. Det här har vi allihop påtalat i ett decennium. Människor höll på att gå under i tio års tid innan den här puckeln. Själva belastningen: Vi har ju köer, vi har långa köer. Om folk ska orka både nu och framåt så behöver samtalen redan nu äga rum om hur man ska organisera vården framåt. Ja, kan man sjösätta 300 miljarder varannan dag i stödpaket, ja, då borde man kunna se till att ha en rimlig vård i vårt dagliga samhälle, innan och efter en sån här situation. Vi gör ett fantastiskt jobb och jag tror att det är nu när den här pandemin har kört i gång, att de förstår att vårdpersonalen behövs. Jag hoppas att man i framtiden har en beredskap för att möta såna här extraordinära situationer, för det har vi inte i dag. Men det inverkar ju på hela sjukvården, även om man inte är direkt drabbad av corona. Ja, jag tror att det kommer bli stor skillnad i hur vi ser på sjukvården. Jag hoppas att det blir annorlunda och att det värdesätts mer. 
Den andra vinjetten beskriver ett narrativt meningsskapande där den akuta situationen förstås som del av en långvarig process. Tidsperspektivet som används som grund för huvudbudskapen i vinjett II är utsträckt - såväl tidigare erfarenheter som reflektioner om en framtid, som inte är specifikt knuten till den specifika situationen, inkluderas i det narrativa meningsskapandet om den situation som pågår just nu. I vinjetten visas hur det narrativa meningsskapandet för arbetsvillkor just nu (Nutid) förmedlas som en konsekvens av en längre tids nedskärningar av resurser inom vård- och omsorgssektorn (Dåtid) och man hoppas att coronapandemin (Nutid) ska innebära att myndigheter och beslutsfattare förstår att en förändring krävs. En sådan förändring tolkas som en förbättringsmöjlighet såväl vad gäller arbetsvillkor som beredskap i händelse av att en ny situation längre fram i tiden skulle kräva likaledes omfattande insatser (Framtid). Hur tid används till stöd för de poänger i berättelsen som knutits till denna vinjett kan beskrivas så här:

Dåtid som grund för poäng om Framtid

Dåtid och Nutid som grund för poäng om Nutid

Dåtid och Nutid som grund för poäng om Framtid

\section{Tid för förändring}

Vad vi har här är två vinjetter, vilka skiljer sig åt i hur poängen i berättelsen förmedlas i relation till tid. De vinjetter som skapats skiljer sig alltså åt i hur det narrativa meningsskapandet knyts och ordnas i relation till tid för att framföra poängerna i berättelserna. Samtidigt ger vinjetterna i huvudsak en gemensam bild av arbetsvillkoren inom vården. I centrum för de tolkningar som görs i båda vinjetterna finns gemensamma mönster vilka ger uttryck för upplevda brister i resurstilldelning och organiseringen av vård- och omsorgssektorn samt ett likartat budskap om att arbetsvillkor inom vård och omsorg behöver förbättras i framtiden. Detta innebär att de båda vinjetterna bygger upp en övergripande gemensam berättelse med budskapet att det är tid för förändring.

\section{Tid och temporalitet i narrativ om arbetsvillkor inom vården}

De båda vinjetter som utgör analysens resultat bygger tillsammans upp en berättelse om behov av generella förbättringar av arbetsvillkor och beredskap inför framtiden, men skiljer sig åt i fråga om huruvida dessa förbättringar ramas in av den aktuella situationen just $n u$ eller beskrivs som en förståelse av det som varit i relation till det som är. Analysen visar att arbetsvillkoren under den första akuta fasen av coronapandemin ges mening som ett uttryck för, å ena sidan, något specifikt och tidsbundet (Vinjett I) och, å andra sidan, en långvarig process (Vinjett II). I vinjetten som ger uttryck för hur mening skapas genom att knyta an till det specifika i situationen fokuseras nuet och framtiden (utan att knyta an till den tid som varit). I vinjetten som visar hur mening skapas av situationen som en del av en långvarig process förmedlas däremot poängen i berättelsen genom att knytas till ett (i tid) utsträckt perspektiv som innefattar dåtid, nutid och framtid. Skillnaden i vinjetterna består således i hur tid används och ordnas i berättelserna. 
Det blir tydligt utifrån den analys som gjorts att framtid utgör en del av meningsskapandet i de båda vinjetterna. Både det narrativa meningsskapande som knyts till den specifikt tidsbundna situationen, beskriven i Vinjett I, och det som knyts till den långvariga processen, visualiserad i Vinjett II, relateras till idéer om framtiden. Denna analys synlig- och tydliggör hur det narrativa meningsskapandet inte begränsas till nuet, utan knyter an såväl bakåt som framåt i tid. I de berättelser som analyserats används erfarenheter i nutid och dåtid för att förstå det som händer nu, samtidigt som de öppnar för tolkningar vad gäller att förutse framtiden jämför med (Cunliffe, Luhmann och Boje 2004:269). Den gemensamma förståelse som framkommer, att det är tid för förändring, inkluderar alltså behov av framtida förbättrade arbetsvillkor inom vård och omsorg och begränsas inte till den i intervjuerna ställda frågan om behov av stöd under den pågående coronapandemin.

Det är intressant att se hur framtida förbättringar vad gäller resurser och organisering lyfts fram i de tolkningar som görs av arbetsvillkoren under de första veckorna av coronapandemin, oavsett tidsperspektiv i de narrativ som analyserats. Vilken framtid som avses skiljer sig dock åt. I vinjett I är tidsperspektivet kortare och det är en framtid relaterad till hanteringen av coronapandemin som lyfts fram. I vinjett II, som illustrerar det mer utsträckta tidsperspektivet, knyts tankar om framtiden inte bara till den situation som följer direkt av coronapandemin utan också till en framtid bortom coronapandemin. Intervjupersonerna konstruerar alltså sina berättelser utifrån de tankar de har om framtiden (jämför med Petranker 2005), i det här fallet önskemål om förbättrade villkor inom vård- och omsorgssektorn. I de båda vinjetterna skapas på detta sätt en förståelse av, och med hjälp av, den framtid som önskas. En framtida förändring av vård- och omsorgssektorn relateras på så vis till såväl förbättrade arbetsvillkor som stärkt beredskap. Det blir tydligt i båda vinjetterna att intentioner som gäller framtiden (Petranker 2005), det vill säga det framåtsyftande meningsskapandet, är viktiga för sätta ramarna för hur den aktuella situationen kan förstås. Värt att notera är att den första vinjetten inte inkluderar det retrospektiva i tolkningen av situationen. Detta skiljer sig från hur meningsskapande vanligen diskuteras (jämför med Weick 1995). Här handlar det således om ett narrativt meningsskapande där framtiden utgör en viktig del av förståelsen i och av situationen just nu, vilket går bortom en förståelse av meningsskapande som fokuserar på ett retrospektivt begripliggörande av en situation (Mackay 2009; Sandberg \& Tsoukas 2014; Brown, Colville \& Pye 2015).

\section{Diskussion}

Genom att analysera narrativt meningsskapande av en aktuell situation, det vill säga arbetsvillkoren under den första tiden av coronapandemin, med utgångspunkt i hur narrativ skapas i relation till tid, har vi kunnat lösgöra oss från den specifika och tydligt tidsbundna situationen. Teorier om narrativ, med särskilt avseende på hur den meningsskapande processen knyts till och ordnas i relation till tid (Cunliffe, Luhmann \& Boje 2004; Pedersen 2009), användes som grund för analysen vilket gjorde det möjligt att förstå den akuta situationen (just nu) i relation till tidigare erfarenheter 
och tankar om arbetsvillkor i ett senare skede, efter pandemin. Det vi här har visat är att de två vinjetter som skapats både berättar om den specifika situationen under den första tiden av coronapandemin och om någonting annat, någonting mer - de ifrågasätter själva organiseringen av vård och omsorg. Den narrativa förståelsen och analysen som fokuserade på hur tid används i berättelserna, i relation till den fråga intervjupersonerna fick, skapade en öppning för att förstå coronapandemin som en händelse som uppmärksammar någonting mer än arbetssituationen just nu, nämligen en kritik av arbetsvillkor inom vården över tid på en övergripande och generell nivå. Denna slutsats är något som har lyfts fram tidigare då det har betonats att arbetsvillkor inom vård och omsorg behöver vara hållbara över tid och inte kan reduceras till den specifika situation och de utmaningar som är specifikt kopplade till coronapandemin (Rieckert, Schuit, Blejenberg m.fl. 2021).

Precis som i många andra studier av hur människor förhåller sig till förändringar inom organisationer har vi fokuserat på hur mening skapas kring en nyuppkommen situation som karaktäriseras av osäkerhet (jämför med Weick 1995). Utöver det bidrag analysen gett i fråga om narrativt meningsskapande inom organisationer, i relation till hur tid ordnas och används, bidrar analysen också till en förståelse av hur arbetsvillkoren inom vården under denna tid beskrevs av intervjupersonerna. Innehållet $\mathrm{i}$ de utsagor som analyserats i denna artikel, vilka tidigare analyserats tematiskt (Wall 2020a), synliggör att organisatoriska förändringar för att hantera pandemin i dess akuta fas utmanar förutsättningarna för arbete inom vård och omsorg. Detta känns igen från tidigare studier som visat att arbete inom denna sektor genomgått snabba förändringar - vad gäller belastning, uppgifter och arbetets förutsättningar - vid tidigare situationer med global smittspridning (se t.ex. Maunder, Leszcz, Savage m.fl. 2008). Att deltagarnas berättelser i vår studie visar att generella arbetsvillkor är centrala vid akut krishantering, såsom under pandemins inledande skede, känns också igen från tidigare studier som betonat att till exempel god bemanning och tillräckliga resurser krävs för att stärka vård- och omsorgssektorns förmåga till god vårdkvalitet också i svåra situationer (Williamsson 2007; Hansen 2014; Rieckert, Schuit, Blejenberg m.fl. 2021).

Vår analys, som knyter deltagarnas berättelser till den specifika och akuta situationen i sig såväl som till generella arbetsvillkor inom vården, visar hur narrativ kopplade till arbetsvillkor under organisationsförändringar kan förstås i relation till ett vidare sammanhang än till en avgränsad händelse. Vi bidrar därmed inte bara med empiriskt grundad kunskap om arbetsvillkor inom vården vid global smittspridning, utan framför allt en fördjupad förståelse av hur narrativt meningsskapande av en akut situation kan relateras till olika förståelser av tid (jämför med Pedersen 2009:390). Mot denna bakgrund ser vi det som problematiskt att coronapandemin i samhällsdiskussionen och forskningen behandlas som något specifikt och av särskilt intresse just nu. Att enbart fokusera på det unika i den akuta situationen kan göra att man missar att den är en del av, och ett uttryck för, en långvarig process som är än mer central för att förstå den specifika situationens villkor. 


\section{Referenser}

Arbetarskyddsstyrelsen. (2000) Stress och belastning i vaird och omsorg. Verksgemensamt tillsynsprojekt 1998 och 1999. Rapport nr 2000:8. Solna: Arbetarskyddsstyrelsen.

Barter, C. \& E. Renold (1999) "The use of vignettes in qualitative research", Social research update 25 (9):1-4.

Bejerot, E. \& H. Hasselbladh (2013) "Forms of intervention in public sector organizations. Generic traits in public sector reforms", Organization studies 34 (9):1357-1380. https://doi.org/10.1177/0170840613477639

Brown, A.D., I. Colville \& A. Pye (2015) "Making sense of sensemaking in organization studies", Organization studies 36 (2):265-277. https://doi. org/10.1177/0170840614559259

Brown, A.D., P. Stacey \& J. Nandhakumar (2008) "Making sense of sensemaking narratives", Human relations 61 (8):1035-1062. https://doi.org/10.1177/0018726708094858

Bruner, J. (1991) "The narrative construction of reality", Critical inquiry 18 (1):1-21. https://doi.org/10.1086/448619

Bäck, H. \& A. Gröjer (1994) Stockholmsmodellen och vårdens effektivitet. Rapport nr. 1994:50. Stockholm: Stockholms universitetet, Institutet för kommunal ekonomi.

Chan, A.O.M. \& C.Y. Huak (2004) "Psychological impact of the 2003 severe acute respiratory syndrome outbreak on health care workers in a medium size regional General Hospital in Singapore", Occupational medicine 54 (3):190-196. https://doi. org/10.1093/occmed/kqh027

Chan, S.S.C., G.M. Leung, A.F.Y Tiwari, F. Salili, S.S.K Leung, D.C.N. Wong, A.S.F. Wong, A.S.F Lai \& T. Hing Lam (2005) "The impact of work-related risk on nurses during the SARS outbreak in Hong Kong", Family and community health 28 (3):274-287. https://doi.org/10.1097/00003727-200507000-00008

Churchman, D. \& S. King (2009) "Academic practice in transition. Hidden stories of academic identities", Teaching in higher education 14 (5):507-516. https://doi. org/10.1080/13562510903186675

Corley, K.G. \& D.A. Gioia (2011) "Building theory about theory building. What constitutes a theoretical contribution?", Academy of management review 36 (1):12-32. https://doi.org/10.5465/amr.2009.0486

Cunliffe, A.L., J.T. Luhmann, \& D.M. Boje (2004) "Narrative temporality. Implications for organizational research", Organization studies 25 (2):261-286. https://doi. org/10.1177/0170840604040038

Currie, G. \& A.D. Brown (2003) "A narratological approach to understanding processes of organizing in a UK hospital", Human relations 56 (5):563-586. https://doi. org/10.1177/0018726703056005003

Czarniawska, B. (1997) Narrating the organization. Dramas of institutional identity. Chicago: University of Chicago Press.

Czarniawska, B. (2005) "Karl Weick. Concepts, style and reflection", The Sociological Review 53 (1):267-278. https://doi.org/10.1111/j.1467-954X.2005.00554.x

Ekengren, J., N.B. Stambulova, U. Johnson, I.-M. Carlsson \& T.V.R. Ryba (2020) 
"Composite vignettes of Swedish male and female professional handball players' career paths", Sport in society 23 (4):595-612. https://doi.org/10.1080/17430437.2 019.1599201

Ely, M., R. Vinz, M. Downing \& M. Anzul (1997) On writing qualitative research. Living by words. London: Falmer press.

Ewick, P. \& S.S. Silbey (1995) "Subversive stories and hegemonic tales. Toward a sociology of narrative", Law \& society review 29 (2):197-226. https://doi. org/10.2307/3054010

Fridner, A., K. Belkic, M. Marini, D. Minucci, L. Pavan, \& K. Schenck-Gustafsson (2009) "Survey on recent suicidal ideation among female university hospital physicians in Sweden and Italy (the HOUPE study). Associations with work stressors", Gender medicine 6 (1):314-328. https://doi.org/10.1016/j.genm.2009.04.006

Fridner, A., K. Belkic, D. Minucci, M. Marini, G. Putoto, P. Simonato, \& K. SchenckGustafsson (2011) "Work environment and recent suicidal thoughts among male university hospital physicians in Europe (HOUPE) study", Gender medicine 8 (4):269-279. https://doi.org/10.1016/j.genm.2011.05.009

Gioia, D.A. (2006) "On Weick. An appreciation", Organization studies 27 (11):1709_ 1721. https://doi.org/10.1177/0170840606068349

Grassi, L., \& K. Magnani (2000) "Psychiatric morbidity and burnout in the medical profession. An Italian study of general practitioners and hospital physicians", Psychotherapy and psychosomatics 69 (6):329-334. https://doi.org/10.1159/000012416

Hall, P. (2012) Managementbyråkrati. Organisationspolitisk makt i svensk offentlig förvaltning. Malmö: Liber.

Hansen, N. (2014) Arbetsvillkor i privat och offentlig sjukvård. Implikationer för personalens attityder och hälsa. Stockholm: Stockholms universitet.

Hings, R.F., C.R.D. Wagstaff, V. Anderson, S. Gilmore, \& R.C. Thelwell (2018) "Professional challenges in elite sports medicine and science. Composite vignettes of practitioner emotional labor", Psychology of sports \& exercise 35:66-73. https://doi. org/10.1016/j.psychsport.2017.11.007

Holley, K. A. \& J. Colyar (2009) "Rethinking texts. Narrative and the construction of qualitative research", Educational researcher 38 (9):680-686. https://doi. org/10.3102/0013189x09351979

Hydén, L.-C. (1997) "De otaliga berättelserna", 9-29 i L.-C. Hydén \& M. Hydén (red.) Att studera berättelser. Samhällsvetenskapliga och medicinska perspektiv. Stockholm: Liber.

Johansson, A. (2005) Narrativ teori och metod. Lund: Studentlitteratur.

Khalid, I., T.J. Khalid, M.R. Qabajah, A.G. Barnard \& I.A. Qushmaq (2016) "Healthcare workers emotions, perceived stressors and coping strategies during a MERS-CoV outbreak", Clinical medicine \& research 14 (1):7-14. https://doi. org/10.3121/cmr.2016.1303

Klein, G., B. Moon \& R. Hoffman (2006) "Making sense of sensemaking. Alternative perspectives", IEEE intelligent systems 21 (4):70-73. https://doi.org/10.1109/ MIS.2006.75 
Koh, D., M.K. Lim, S.E. Chia, S.M. Ko, F. Qian, V. Ng, B.H. Tan, K.S. Wong, M.W. Chew, H.K. Tang, W. Ng, Z. Muttakin, S. Emmanuel, N.P. Fong, G. Koh, C.T. Kwa, K.B-C. Tan \& C. Fones (2005) "Risk perception and impact of severe acute respiratory syndrome (SARS) on work and personal lives of healthcare workers in Singapore", Medical care 43 (79):676-682. https://doi.org/10.1097/01. mlr.0000167181.36730.cc

Labov, W. \& D. Fanshel (1977) Therapeutic discourse. Psychotherapy as a conversation. New York: Academic Press.

Lee, S-H., Y.-Y. Juang, Y.-J. Su, H.-L. Lee, Y.-H. Lin \& C.-C. Chao (2005) ”Facing SARS. Psychological impacts on SARS team nurses and psychiatric services in a Taiwan General Hospital”, General hospital psychiatry 27 (5):352-358. https://doi. org/10.1016/j.genhosppsych.2005.04.007

Leiter, K.A. (1980) A primer on ethnomethodology. New York: Oxford University Press.

MacIntyre, A. (1981) After virtue. South Bend: Notre Dame university press.

MacKay, R.B. (2009) "Strategic foresight. Counterfactual and prospective sensemaking in enacted environments", 90-112 i L.A. Costanzo \& R.B. MacKay (red.) Handbook of research on strategy and foresight. Cheltenham: Edward Elgar publishing. https:// doi.org/10.4337/9781848447271.00011

Maitlis, S. (2005) "The social processes of organizational sensemaking", Academy of management journal 48 (1):21-49. https://doi.org/10.2307/20159639

Maunder, R. (2004) "The experience of the 2003 SARS outbreak as a traumatic stress among frontline healthcare workers in Toronto. Lessons learned", Philosophical transactions of the royal society B 359 (1447):1117-1125. https://doi.org/10.1098/ rstb.2004.1483

Maunder, R., J. Hunter, L. Vincent, J. Bennett, N. Peladeau, M. Leszcz, J. Sadavoy, L.M. Verhaeghe, R. Steinberg \& T. Mazzulli (2003) "The immediate psychological and occupational impact of the 2003 SARS outbreak in a teaching hospital", Canadian medical association journal 168 (10):1245-1251.

Maunder, R.G., M. Leszcz, D. Savage, M.A. Adam, N. Peadeau, D. Romano, M. Rose \& R.B. Schulman (2008) "Applying the lessons of SARS to pandemic influenza", Canadian journal of public health 99:486-488. https://doi.org/10.1007/ BF03403782

McAlonan, G.M., A.M. Lee, V. Cheung, C. Cheung, K.W.T. Tsang, P.C. Sham, S.E. Chua \& J.G.W.S. Wong (2007) "Immediate and sustained psychological impact of an emerging infectious disease outbreak on health care workers", Canadian journal of psychiatry 52 (4):241-247. https://doi.org/10.1177/070674370705200406

McAlpine, L. (2016) "Why might you use narrative methodology? A story about narrative", Easti haridusteaduste ajakiri 4 (1):32-57. https://doi.org/10.12697/ eha.2016.4.1.02b

Målqvist, I., C. Åborg \& M. Forsman (2011) Styrformer och arbetsförhållanden inom vård och omsorg. En kunskapssammanställning om new public management. Rapport nr 2011:11. Stockholm: Karolinska institutet, Institutionen för folkhälsovetenskap. O’Boyle, C., C. Robertson \& M. Secor-Turner (2006) "Public health emergencies. 
Nurses' recommendations for effective actions", AAOHN journal 54 (8):347-353. https://doi.org/10.1177/216507990605400802

Pedersen, A.R. (2009) "Moving away from chronological time. Introducing the shadows of time and chronotopes as new understandings of 'narrative time"', Organization 16 (3):389-406. https://doi.org/10.1177/1350508409102302

Petranker, J. (2005) "The when of knowing", The journal of applied behavioral science 41 (2):241-259. https://doi.org/10.1177/0021886305274757

Polkinghorne, D.E. (1988) Narrative knowing and the human sciences. Albany: State University of New York.

Ricoeur, P. (1984) Time and narrative. Chicago: University of Chicago Press.

Rieckert, A., E., Schuit, N. Bleijenberg, D. ten Cate, W. de Lange, J.M. de Man-van Ginkel, E. Mathijssen, L.C. Smit, D. Stalpers, L. Schoonhoven, J.D. Veldhuizen \& J.C.A. Tappenburg (2021) "How can we build and maintain the resilience of our health care professionals during COVID-19? Recommendations based on a scoping review", BMJ open 11:e043718. https://doi.org/10.1136/bmjopen-2020-043718

Sandberg, J. \& H. Tsoukas (2014) "Making sense of the sensemaking perspective. Its constituents, limitations and opportunities for further development", Journal of organizational behavior 36 (S1):6-32. https://doi.org/10.1002/job.1937

Schinke, R. J., A.T. Blodgett, K.R. McGannon \& Y. Ge (2016) "Finding one’s footing on foreign soil. A composite vignette of elite athlete acculturation", Psychology of sport \& exercise 25:36-43. https://doi.org/10.1016/j.psychsport.2016.04.001

Smith, B. (2016) "Narrative analysis. How can it be done?", 260-273 i B. Smith \& A. Sparkes (red.) Routledge handbook of qualitative research in sport and exercise. London: Routledge. https://doi.org/10.4324/9781315762012-31

Son, J., A. Erno, D.G. Shea, E.E. Femia, S.H. Zarit \& M.A. \& P. Stephens (2007) "The caregiver stress process and health outcomes", Journal of aging and health 19 (6):871-887. https://doi.org/10.1177/0898264307308568

Son, H., W.J. Lee, H.S. Kim, K.S. Lee \& M. You (2019) "Hospital workers' psychological resilience after the 2015 Middle East respiratory syndrome outbreak", Social behavior and personality 47 (2):1-13. https://doi.org/10.2224/sbp.7228

Spalding, N. \& T. Phillips (2007) "Exploring the use of vignettes. From validity to trustworthiness", Qualitative health research 17 (7):954-962. https://doi. org/10.1177/1049732307306187

Speroni, K.G., D. Seibert \& R.K. Mallinson (2015a) "Nurses' perception on Ebola care in the United States", The journal of nursing administration 45 (11):544-550. https://doi.org/10.1097/NNA.0000000000000261

Speroni, K.G., D. Seibert \& R.K. Mallinson (2015b) "US nurses' perceptions regarding caring for suspected, probable, and confirmed Ebola virus disease patients", The journal of nursing administration 45 (10):477-484. https://doi.org/10.1097/ NNA.0000000000000238

Starbuck, W. \& F. Milliken (1988) "Executive perceptual filters. What they notice and how the make sense", 35-66 i D. Hambrick (red.) The executive effect. Concepts and methods for studying top management. Greenwich: JAI. 
Tam, C., E. Pang, L. Lam \& H. Chiu (2004) "Severe acute respiratory syndrome (SARS) in Hong Kong in 2003. Stress and psychological impact among frontline healthcare workers", Psychological medicine 34 (7):1197-1204. https://doi. org/10.1017/S0033291704002247

Tolomiczenko, G.S., M. Kahan, M. Ricci, L. Strathern, C. Jeney, K. Patterson \& L. Wilson (2005) "SARS. coping with the impact at a community hospital", Journal of advanced nursing 50 (1):101-110. https://doi.org/10.1111/j.1365-2648.2005.03366.x

Vetenskapsrådet. (2017) God forskningssed. Stockholm: Vetenskapsrådet.

Wall, E. (2010) Riskförståelse. Teoretiska och empiriska perspektiv. Östersund: Mittuniversitetet.

Wall, E. (2020a) Hellre en rimlig jobbsituation än applåder. Vårdpersonalens budskap om arbetssituationen under den första tiden av smittspridning av Coronaviruset $i$ Sverige 2020. Mittuniversitetet: Östersund.

Wall, E. (2020b) "Vårdpersonalens coronavardag”. Projektbeskrivning, diarienummer MIUN 2020/1393. Mittuniversitetet, Östersund.

Weick, K. (1995) Sensemaking in organizations. Thousand Oaks: Sage.

Weick, K. E., K.M. Sutcliffe \& D. Obstfeld (2005). "Organizing and the process of sensemaking", Organization science 16 (4):409-421. https://doi.org/10.1287/ orsc. 1050.0133

Wilkins, A. \& M.P. Thompson (1991) "On getting the story crooked (and straight)", Journal of organisational change management 4 (3):18-26. https://doi.org/10.1108/ EUM0000000001194

Williamson, K.M. (2007) "Home health care nurses' perceptions of empowerment", Journal of community health nursing 24 (3):133-153. https://doi. org/10.1080/07370010701429512

Wong, T.W., J.K.Y. Yau, C.L.W. Chan, R.S.Y. Kwong, S.M.Y. Ho, C.C. Lau, F.L. Lau \& C.H. Lit (2005) "The psychological impact of severe acute respiratory syndrome outbreak on healthcare workers in emergency departments and how they cope", European journal of emergency medicine 12 (1):13-18. https://doi. org/10.1097/00063110-200502000-00005

WHO (2020) Mental health and psychosocial considerations during the COVID-19 outbreak, 18 March 2020. Genève: Världshälsoorganisationen.

Wu, P., Y. Fang, Z. Guan, B. Fan, J. Kong, Z. Yao, X. Liu, C.J. Fuller, E. Susser \& C.W. Hoven (2009) "The psychological impact of the SARS epidemic on hospital employees in China. Exposure, risk perception, and altruistic acceptance of risk", Canadian journal of psychiatry 54 (5):302-311. https://doi.org/10.1177/070674370905400504

Ybema, S. (2010) "Talk of change. Temporal contrasts and collective identities", Organization studies 31 (4):481-503. https://doi.org/10.1177/0170840610372205

Öhrming, J., \& M. Sverke (2001) Bolagiseringen av S:t Görans sjukhus. En proaktiv organisering. Lund: Studentlitteratur. 


\section{Författarpresentation}

Erika Wall är docent i sociologi och universitetslektor i rehabiliteringsvetenskap vid Institutionen för hälsovetenskap, Mittuniversitetet. Hennes forskning fokuserar på arbetsliv, hälsa och rehabilitering. Just nu bedriver hon två projekt med hälsofrämjande perspektiv på risk och trygghet i arbetslivet. Det ena handlar om arbetsvillkor inom vården och det andra om unga vuxnas introduktion på arbetsmarknaden.

Jonny Bergman är filosofie doktor i sociologi och universitetslektor i sociologi vid Institutionen för humaniora och samhällsvetenskap, Mittuniversitetet. Hans forskningsintressen rör framför allt hur privilegierade och normaliserade positioner och ageranden kan förstås och utmanas, bland annat med fokus på tid, temporalitet och motstånd inom ramen för arbetslivet.

\section{Kontaktuppgifter}

Erika Wall

Institutionen för hälsovetenskap

Mittuniversitetet, 83125 Östersund

erika.wall@miun.se 